Sex Plant Reprod (1990) 3:23-30

\title{
Sexual differentiation in Asparagus officinalis L.
}

\section{Total and newly synthesized proteins in male and female flowers}

\author{
M. Bracale ${ }^{1}$, M.G. Galli ${ }^{1}$, A. Falavigna ${ }^{2}$, and C. Soave ${ }^{3}$ \\ ${ }^{1}$ Centro di Studio del C.N.R. per la Biologia Cellulare e Molecolare delle Piante, Dipartimento di Biologia, \\ Sezione Botanica Generale, Via Celoria, 26, I-20133 Milan, Italy \\ ${ }^{2}$ Istituto Sperimentale di Orticultura, Via Paullese, 28, I-20075 Montanaso Lombardo (Milan), Italy \\ ${ }^{3}$ Istituto di Biologia Agraria, Università della Basilicata, Via N. Sauro, 85, I-85100 Potenza, Italy
}

\begin{abstract}
Summary. Sexual dimorphism in the dioecious plant Asparagus officinalis L. was examined by two-dimensional (2-D) electrophoresis of both total proteins and newly synthesized proteins from cladophylls ("leaves"), whole mature flowers and homologous sex organs (i.e. true female ovaries and small sterile ovaries from male flowers). Polypeptides isolated from cladophylls of male and female plants were practically indistinguishable; the flowers, however, showed a distinct set of specific proteins, some of which differed between the two sexes. While the total protein profiles of isolated ovaries from male and female plants were very similar, the patterns were strikingly different after the tissues were pulsed with ${ }^{35} \mathrm{~S}$-methionine: mature male ovaries showed a number of newly synthesized proteins, while in female ovaries only a few molecular species were actively synthesized.
\end{abstract}

Key words: Asparagus - 2-D electrophoresis Dioecy - Flower polypeptides.

\section{Introduction}

Flowering is a complex process involving the generation of the germ line and the organs for sexual reproduction. The differentiation programme, although responsive to several environmental influences, is primarily under genetic control. In dioecious plants, for example, the genes required for the morphogenesis of stamens and pistils are present in both sexes, but the male and female individuals differ in a set of regulatory genes controlling the appearance of the respective reproductive organs (Westergaard 1958; Frankel and Galun 1977). The study of this sex-specific modulation

Offprint requests to: M.G. Galli of gene expression, together with the messages responsible for and accompanying floral differentiation, is an important step in understanding plant development. Recent publications have reported the isolation of a number of floral specific sequences from various species (Goldberg 1989; Simoens et al. 1988; Gasser et al. 1989; MeeksWagner et al. 1989).

We have chosen the process of floral differentiation in Asparagus officinalis as a model system for studying sex organ differentiation in plants. $A s$ paragus is a dioecious species in which the pathway of flower development is remarkably similar in both male and female plants until a stage near meiosis. At this stage the flowers of both sexes contain primordia of both stamens and pistils. Soon thereafter, however, the stamens degenerate and pistils develop in female plants, while in male plants, the pistils stop growing (but do not degenerate) and the stamens continue to develop (Lazarte and Palser 1979).

In a previous paper (Galli et al. 1988) we analyzed the 2-D PAGE patterns of polypeptides produced in vitro by mRNAs of young and mature flowers from female and male Asparagus plants. Sex-specific mRNAs were observed mainly in mature flowers and their cloning is at present under way. While relatively large masses of tissue needed in mRNA isolation prevented the analysis of $\mathrm{mRNAs}$ from sex-specific organs (i.e. anthers and ovaries of both sexes), this can be accomplished by analyzing the 2-D PAGE pattern of total proteins and of newly synthesized proteins (after pulsing the tissue with ${ }^{35} \mathrm{~S}$-methionine), since only a few milligrams of tissue are needed for this technique. Using this approach, we compared the polypeptide patterns of (1) cladophylls (leaves) from male and female plants, (2) whole mature flowers of both sexes and (3) homologous sexual organs 
(true female ovaries and small sterile ovaries from male flowers) in order to learn for how long in ontogeny the pattern of gene expression is similar in the homologous organs of the two sexes. Histological analyses were performed in parallel on male and female organs.

\section{Material and methods}

\section{Plant material}

Asparagus officinalis L. male and female plants (line UC) having very similar genetical backgrounds were used. The plants were grown in open fields. Leaves were collected at a comparable stage of development from male and female plants, and flowers were collected at maturity: male flowers with completely developed but still unopened anthers; female flowers with enlarged but unfertilized pistils (still closed corollas). Female ovaries and rudimentary male ovaries as well as male anthers were removed under a stereo microscope. Leaves, whole flowers or specific sex organs were immediately used for fixing and histological analysis or for pulsing with ${ }^{35} \mathrm{~S}$-methionine and protein extraction.

\section{Histological procedures and "pulsing" with labelled methionine}

Male and female anthers and male and female ovaries were fixed in $3 \%$ glutaraldehyde for $3 \mathrm{~h}$, washed in phosphate buffer, dehydrated, embedded in Epon-Araldite (Mollenhouer 1964) and sectioned ( $1-\mu \mathrm{m}$ thick sections) by a Reichert ultramicrotome. In some experiments samples were treated, before fixation, with ${ }^{3} \mathrm{H}$-methionine (specific activity: $5 \mathrm{Ci} / \mathrm{mmol}$ ) at a concentration of $30 \mu \mathrm{Ci} / \mathrm{ml}$ in a final volume of $0.5 \mathrm{ml} / \mathrm{ten}$ ovaries (approximately). Slides with sections were then autoradiographed using NTB2 emulsion (Galli 1984).

To clear the tissues to show vascular elements, male and female flowers stripped of sterile parts were stained in fuchsin according to the procedure of Fuchs (1963).

${ }^{35} \mathrm{~S}-\mathrm{Methionine}$ (specific activity $>800 \mathrm{Ci} / \mathrm{mmol}$ ) for labelling newly synthesized proteins was applied for $4 \mathrm{~h}$ at room temperature at a concentration of $120 \mu \mathrm{Ci} / \mathrm{ml}$ in a final volume of $3 \mathrm{ml}$ water $/ 100 \mathrm{mg}$ tissue. After a thorough washing with water, the samples were used for protein extraction. In some experiments proteins were also extracted from untreated samples.

\section{Polypeptide extraction and electrophoresis procedure}

Samples $(100 \mathrm{mg})$ were ground in liquid nitrogen in a chilled mortar and extracted in $800 \mu 10.5 \mathrm{M}$ TRIS-HCl, ph 7.5, $0.1 \mathrm{M}$ $\mathrm{KCl}, 0.05 M$ EDTA, $0.7 M$ sucrose and $2 \%(v / v)$ mercaptoethanol. An equal volume of water-saturated phenol was added, and samples were shaken for $10 \mathrm{~min}$ at room temperature. The phases were separated by centrifugation: the phenol phase was recovered, and the aqueous phase re-extracted with an equal volume of water-saturated phenol. Proteins were precipitated from the phenol phase by adding 5 volumes of cold $0.1 \mathrm{M}$ $\mathrm{NH}_{4}$ acetate dissolved in methanol and storing samples at $-20^{\circ} \mathrm{C}$ overnight. The precipitate was pelleted by centrifugation at $11,000 \mathrm{~g}$ for $10 \mathrm{~min}$ at $4^{\circ} \mathrm{C}$, and then washed twice with $0.1 \mathrm{M} \mathrm{NH} \mathrm{NH}_{4}$ acetate in methanol and once with cold acetone
(Hurkman and Tanaka 1986). The pellet was dried and dissolved in $100 \mu$ l lysis buffer (O'Farrell 1975). Before being loaded on a gel, the samples were clarified by centrifugation. Electrophoresis in the first and second dimension were carried out as described by Galli et al. (1988). After electrophoresis, the gels were stained by combined Coomassie blue G-250 and silver stain procedure (De Moreno et al. 1985). After staining and photographing, the gels were fixed in 30\% methanol-10\% acetic acid for $30 \mathrm{~min}$, soaked three times in DMSO for $30 \mathrm{~min}$, once in DMSO + PPO for $3 \mathrm{~h}$ and washed in water for $30 \mathrm{~min}$. Gels were then dried and exposed for at least 20 days.

At least three gels, corresponding to independent protein extracts, were examined for every sample type; patterns were highly reproducible. Moreover, stained protein patterns were unchanged, irrespective of a previous treatment with labelled precursor or not.

\section{Results}

\section{Histological data}

The appearance of male and female ovaries and anthers at a mature stage of development is shown in Fig. 1. Female anthers (Fig. 1C) were shrunken and collapsed, while male ovaries (Fig. 1D), except for their small size and aborted ovules, were characterized by apparently healthy tissues and their resemblence to female ovaries. Different patterns of vascularization characterized the sex organs: in female flowers the vascular bundles were well-developed up to the style (Fig. 1E), while in male flowers they extended only to the proximal part of the rudimentary ovary (Fig. 1 F). With respect to stamen vascularization the opposite situation appeared: female stamen bundles were very small and lacked mature xylem elements.

\section{Comparison of two-dimensional protein patterns}

Total proteins. Figure 2 shows the patterns of total proteins from cladophylls and whole flowers of male and female plants collected at the same stage of development. Cladophyll patterns (A, B) were almost identical between sexes but differed from those of whole flowers $(C, D)$ : several spots which were present in leaves were absent in flowers, and vice versa. In addition, male and female flowers differed from each other quite extensively (arrows indicate major spots present in one sex and absent, or drastically reduced in intensity, in the other).

One of the purposes of our study was to compare the protein patterns of sex-specific organs (i.e. anthers and ovaries) from male and female flowers. In mature female flowers the ovary was fully developed, while in male flowers this organ was rudimentary and strongly reduced in size (Fig. $1 \mathrm{~B}, \mathrm{D}$ ); the homologous pattern of total proteins, however, was remarkably similar between the organs from 


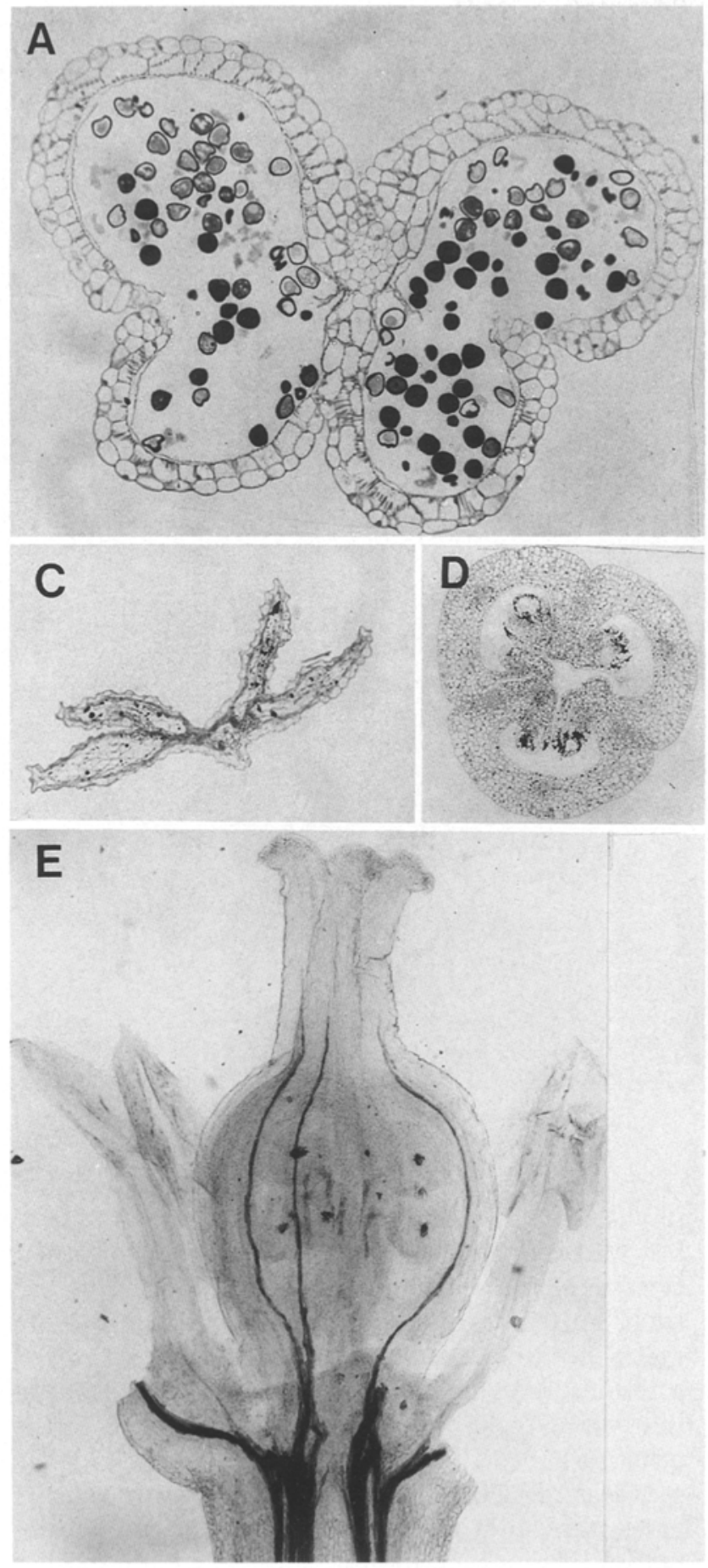

Fig. 1A-F. Appearance of anthers and ovaries from mature flowers: A, D anthers and ovaries, respectively, from male flower; $\mathbf{B}, \mathbf{C}$ from female flower. $\mathbf{E}, \mathbf{F}$ Whole ovaries from female (E) flower and whole anthers from male (F) flower treated to visualize the differential development of the vascular elements
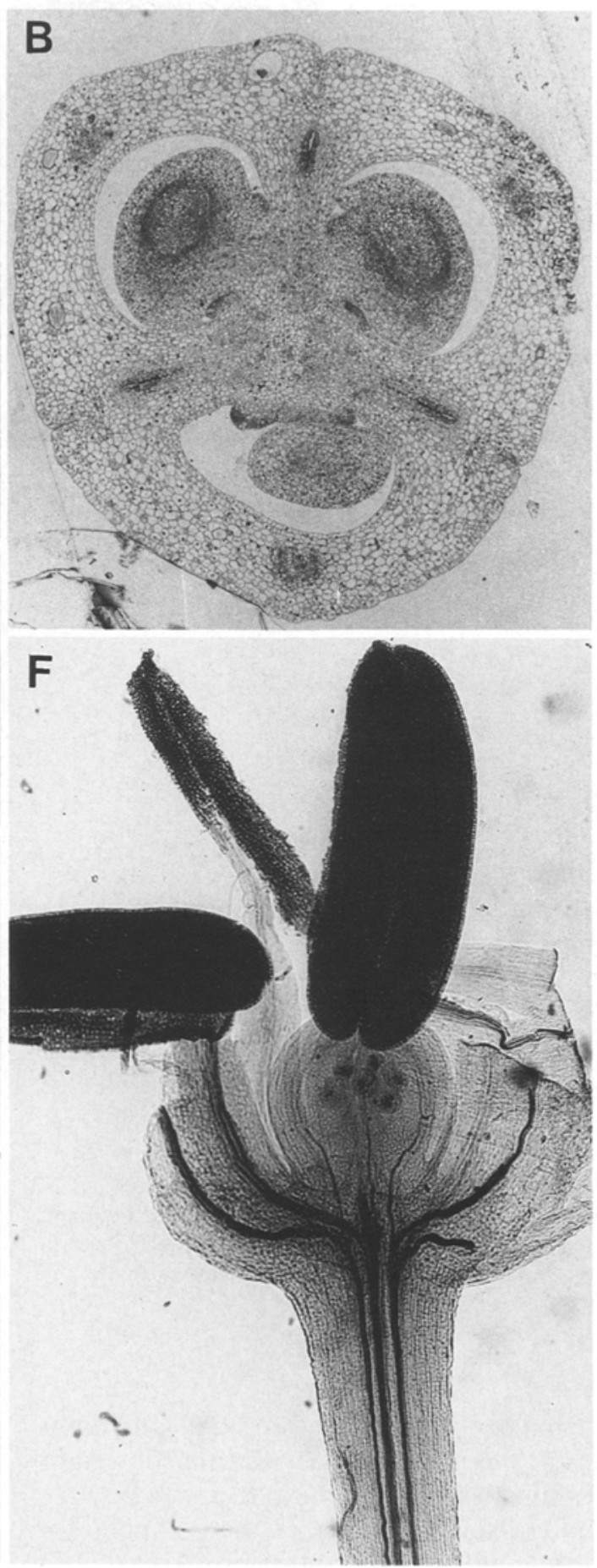

the two sexes, with only few differences, and these mainly quantitative (Fig. $3 \mathrm{~A}, \mathrm{~B}$ ). Some of the ovary proteins were recognizable in the patterns from the whole female flower and from the leaves. However, both male and female whole flowers exhibited spots not present in the ovaries or stamens (likely tepal-specific proteins).

The profile of the male anthers is shown in 


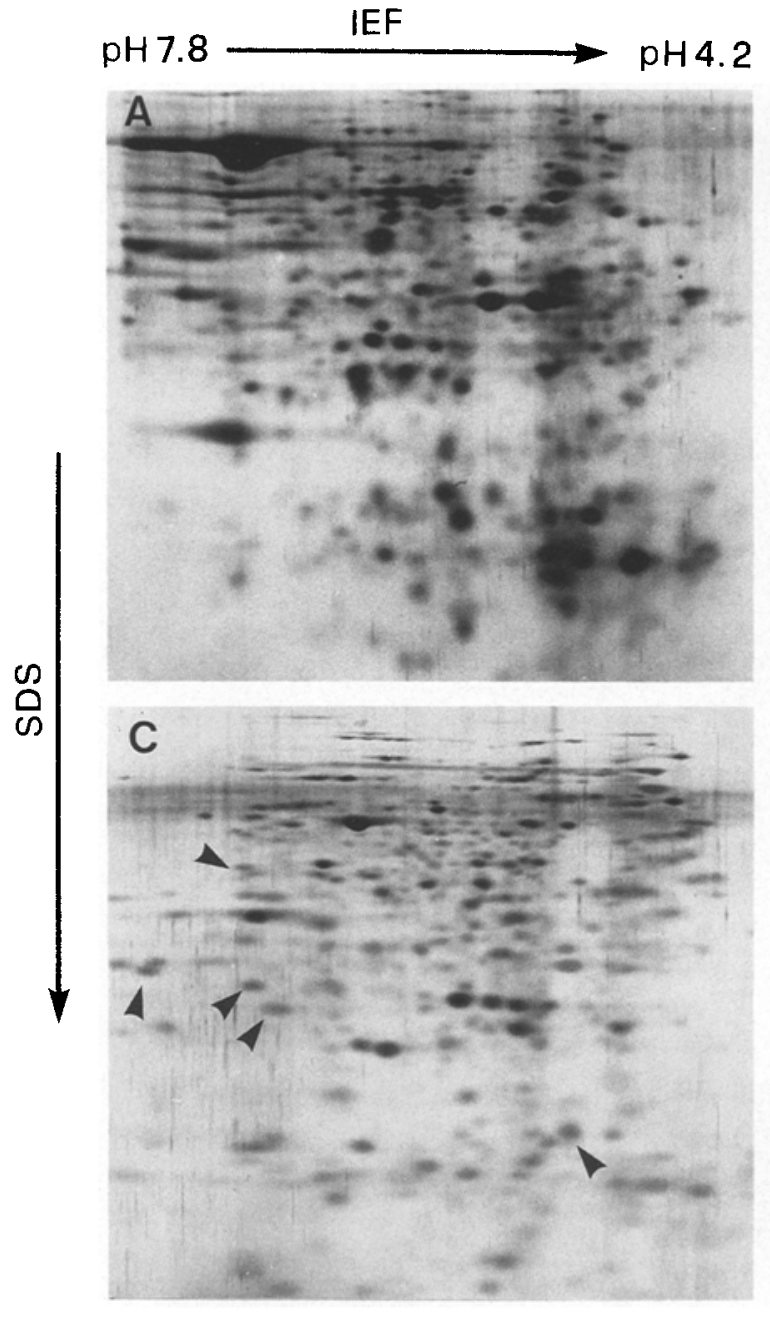

Fig. 2A-D. 2-D gel electrophoresis of polypeptides from cladophylls $(\mathbf{A}, \mathbf{B})$ and flowers $(\mathbf{C}, \mathbf{D})$ of the male and female plant, respectively. Spots were visualized by Coomassie blue-silver staining. Arrows indicate spots that differ between male and female flowers

Fig. 3C (female anthers were so small and light that it was not possible to collect a sufficient weight of them for analysis). The pattern seems to be very specific: only a small number of the polypeptides are in common with those from the ovaries.

Newly synthesized proteins. Although autoradiographed gels were mostly the same as those previously used for staining, a difference in the patterns of total and newly synthesized proteins was observed in all cases. The profiles of "pulsed" proteins from the cladophylls of male and female plants were on the whole very similar (data not shown); those from male and female whole flowers
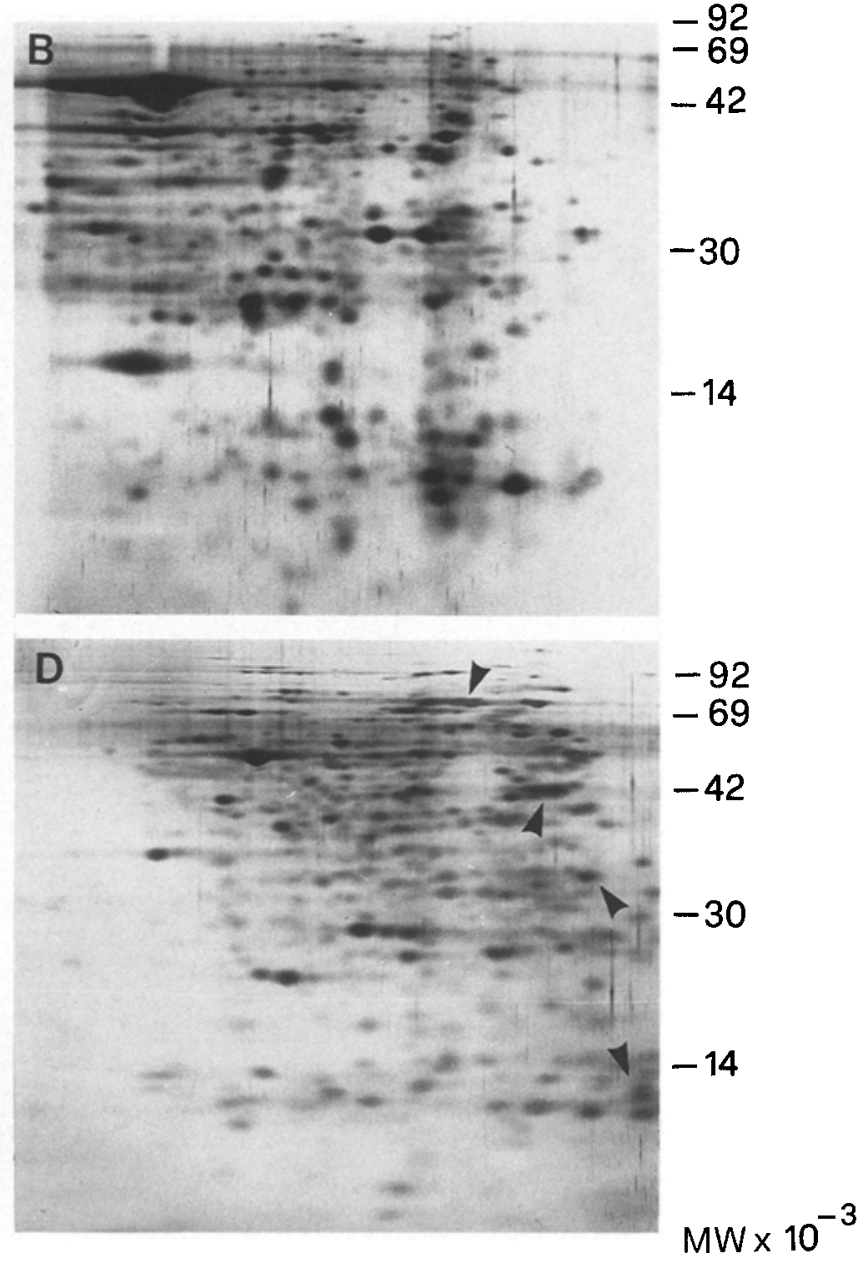

(Fig. 4A, B) were distinctly different from cladophylls and between sexes.The sex-specific spots, however, do not correspond, as judged from their electrophoretic position, to those observed in the total protein profiles. Anthers (only those from males, for the reason mentioned above), showed a reduced and highly specific polypeptide pattern that was largely different from the patterns of the other organs (Fig. 4C). A comparison of newly synthesized proteins in male and female ovaries gave more unexpected results: while male ovaries pulsed with ${ }^{35} \mathrm{~S}$-methionine showed a high number of spots, several of which were also recognizable in the male whole flower pattern, only very few spots were present in mature, unfertilized female ovaries, as if their metabolic activity was greatly reduced at this stage (Fig. 5A, B). Both patterns were highly reproducible. Autoradiographic analysis under the light microscope of sections of ${ }^{3} \mathrm{H}$ methionine-treated female and male ovaries seemed to confirm these findings (Fig. 5C, D). Fe- 


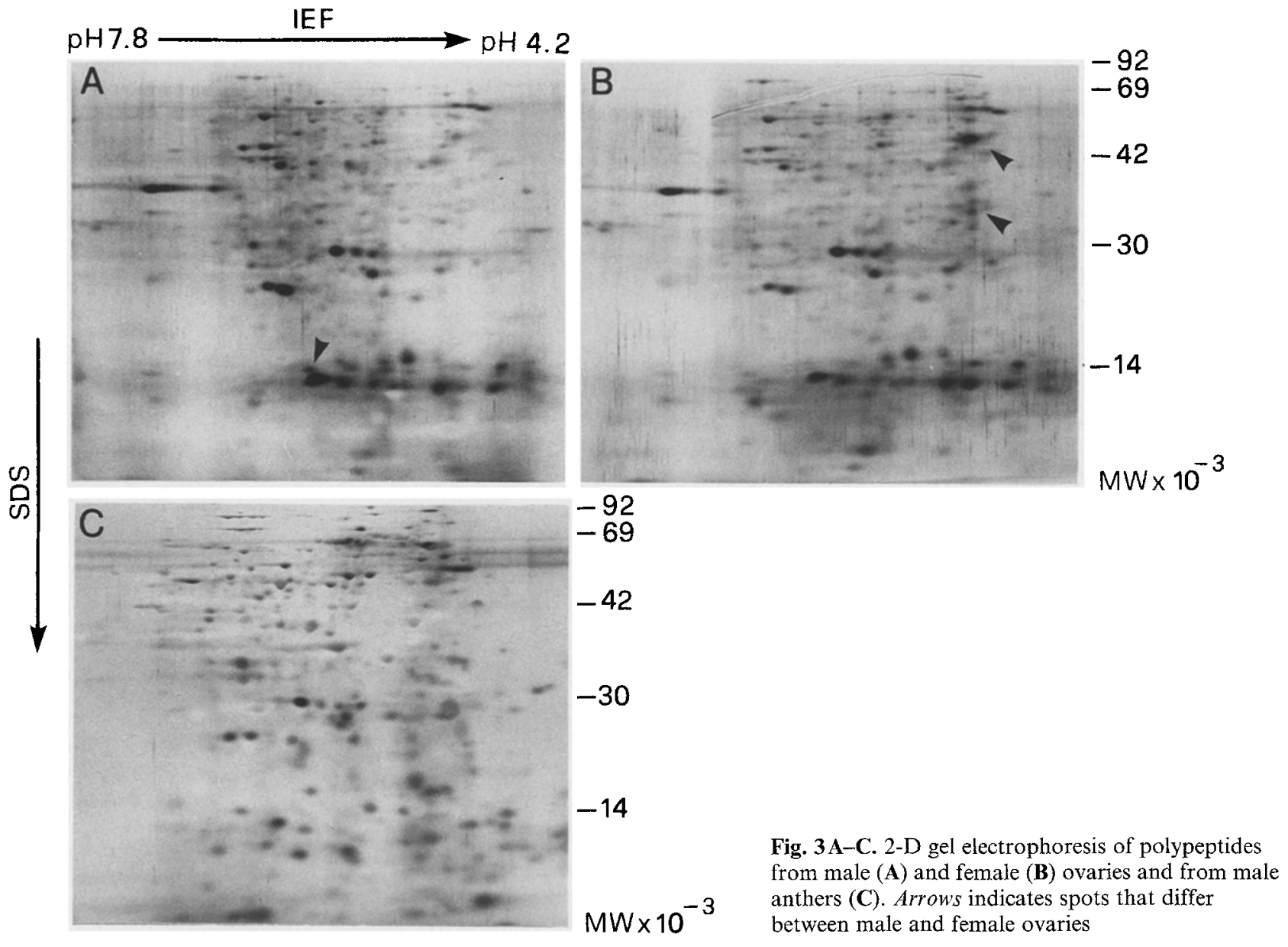

male ovary cells showed a comparable rate of labelling from the external to the internal layers, ruling out the possibility of impaired uptake of the labelled precursor owing to its larger size. The number of silver grains per cell was indeed higher in male ovary parenchymatic cells $(30.1+2.1 \mathrm{com}-$ pared to $17+1.4$ in female ovary cells), while cell dimensions in the two types of ovaries were comparable.

\section{Discussion}

The genetic factors controlling sex differentiation in Asparagus are largely unknown. Earlier studies, however, have associated the sex determinants to the homomorphic chromosome pair number 5 (Loptien 1979) and, on the basis of the rare occurrence in the progeny of hermaphroditic and "neuter" plants (neither male, nor female), a model for sex determination analogous to the one proposed by Westergaard in Silene (1958) has been proposed (Marks 1973). The model predicts the action of two linked genes, a dominant suppressor of female flowers and a dominant activator of male flowers, with the male being heterozygous for both factors and the female homozygote recessive. The rare occurrence of crossing-over between the two genes will produce hermaphroditic and neuter plants.

Whatever the genetic system controlling sex, the expression of sex-controlling genes in Asparagus occurs later in development. Until meiosis the floral primordia of male and female plants are indistinguishable, but thereafter they undergo different morphogenetic pathways: in the male, the ovaries stop growing while the anthers fully develop; in the female, the anthers degenerate and the ovaries continue to grow. Given this developmental process, we expect to find at least three types of specific messages in Asparagus flowers of both sexes: (1) messages specific to the vegetative parts of the flowers (receptacle, tepals); these messages should likely be common to both sexes and, underrepresented or not, should be present in the rest of the plant; (2) true sexual specific messages; that is, those related to stamens and pistils and obviously differing in mature male and female flowers; (3) messages whose presence or absence is in- 


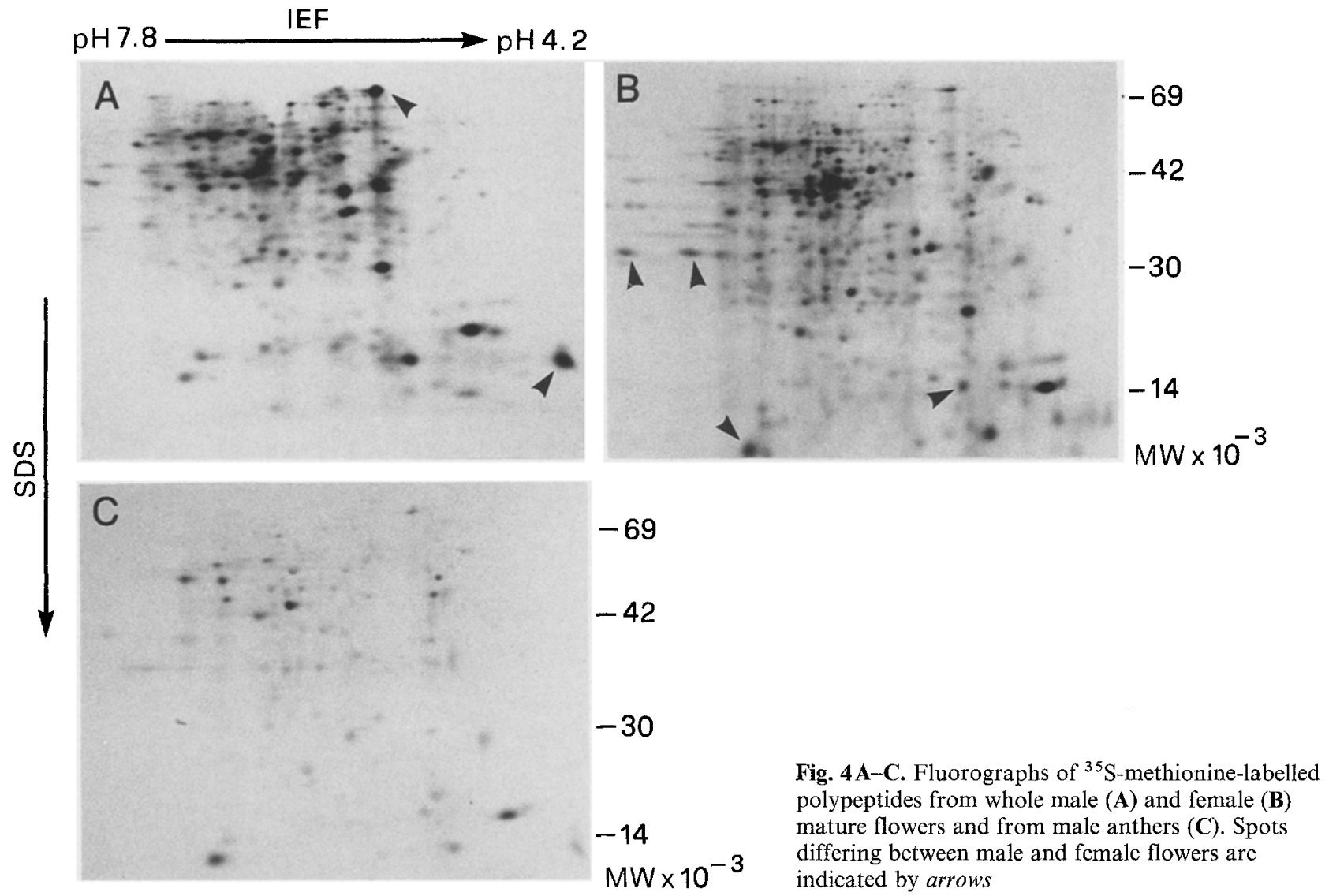

volved in sustaining or in preventing the growth of the homologous organs in the two sexes.

The protein profiles of floral organs shown in this paper confirm some of these expectations, as will be discussed below.

Our results indicate that cladophyll polypeptides from male and female plants are practically indistinguishable. This suggests that, at this level of analysis and in this tissue, secondary sexual traits are not expressed. Furthermore, pair-wise comparison of the 2-D profiles of total proteins from "leaves" with those from whole flowers showed the presence of common and "floral specific" polypeptides. This is not surprising since flowers are composite structures, with some parts being vegetative appendages and others directly involved in sexual reproduction (stamens, pistils). Among the "common" polypeptides, some were found to be present in approximately the same relatively amounts in leaves, whole flowers and also in isolated ovaries, these likely represent housekeeping proteins. Others were drastically reduced in flower profiles with respect to "leaf" profiles. These proteins are possibly confined only to the "vegetative" parts of the flowers and thus appear underrepresented in whole flower profiles.
Flowers were observed to contain a distinct set of polypeptides that were not present in the cladophylls: these floral-specific proteins were mainly associated with the reproductive organs, and secondarily with the tepals. Although we did not analyze these last organs separately, this conclusion can be inferred from the fact that not all the floral specific proteins present in whole flower profiles could be recovered in profiles from ovaries and anthers. In addition, flower profiles differed between the two sexes at the level of either the whole flowers or the isolated ovary. Pair-wise comparison of isolated anthers could not be made because anthers in female flowers degenerate early in development.

The most interesting comparison was the one between the ovaries of the male and female plants because although this organ is drastically reduced in size in the male, it is apparently a healthy and non-senescing tissue. The total protein profiles of the two organs on an equal fresh weight basis were similar with only a few spots that were present in the female being absent or greatly reduced in the male flowers. However, upon pulsing the tissues with ${ }^{35}$ S-methionine and subsequently analyzing the newly synthesized proteins, we observed 


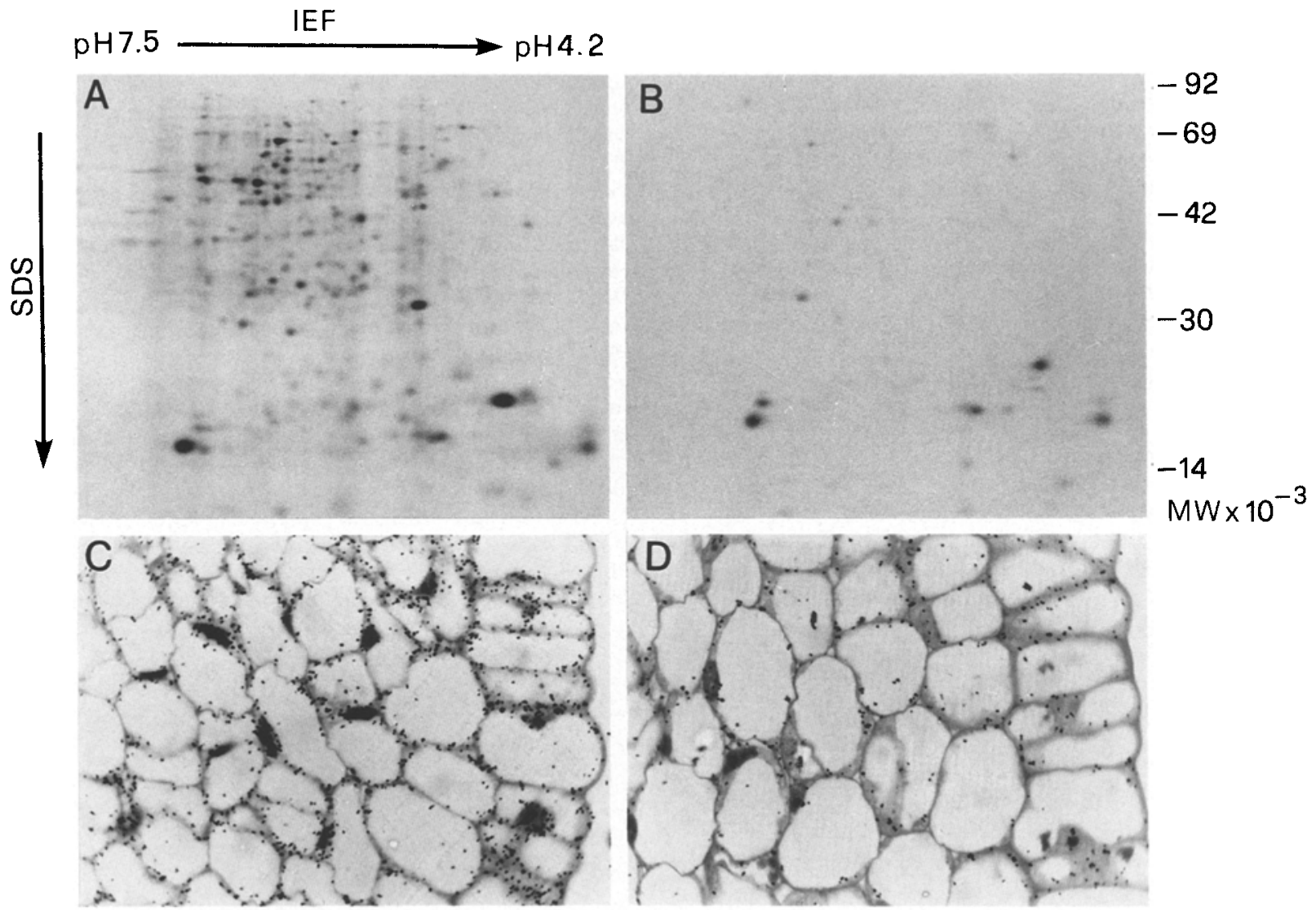

Fig. 5. A, B Fluorographs of ${ }^{35} \mathrm{~S}$-methionine-labelled polypeptides from mature male and female ovaries, respectively. $\mathbf{C}$, D Autoradiographed sections from male (C) and female (D) ovaries pulsed for $4 \mathrm{~h}$ with ${ }^{3} \mathrm{H}$-methionine

that in female ovaries at this stage of development active protein synthesis is limited to very few molecular species, while in male tissue multiple messages are being translated to produce hundreds of different proteins. This result can not apparently be ascribed to a reduced uptake of label by the female ovary since: (1) the number of cpm found in protein fractions extracted from pulsed male and female ovaries was roughly the same when compared on an equal fresh weight base and (2) autoradiographic analyses showed a good penetration of the label in the two tissues. Even if there is a larger methionine pool in the female ovary cells than in the male ovary cells (and then a corresponding reduced internal specific activity), if the protein synthesizing machinery of female ovaries is translating several distinct messages, we should expect the appearance of a number of different proteins in the 2-D gel, albeit with a reduced intensity.

This finding seems to indicate that the female ovary at this stage of development is synthesizing only a reduced set of specific proteins. However, the messages for many more products are also present, indicated by 2-D analysis of the proteins synthesized in vitro by mRNAs of ovaries of corresponding ages (Galli et al. 1988). Thus, a translational control of gene expression seems to be operating in this tissue. In males, however, the profiles of "pulsed" and in vitro-synthesized proteins from purified mRNAs were both characterized by the presence of a number of different products, suggesting that all the messages are actively translated. The absence of a translational control in male ovaries could be one of the causes of their inability to proceed in development.

Acknowledgement. Research supported in part by the Italian Ministry of Agriculture with in the framework of the national research project: development of advanced technologies in agricultural plants.

\section{References}

De Moreno MR, Smith JF, Smith RV (1985) Silver staining of proteins in polyacrylamide gels: increased sensitivity through a combined Coomassie blue-silver stain procedure. Anal Biochem 151:466-470 
Frankel R, Galun E (1977) Pollination mechanisms, reproduction and plant breeding. In: Frankel R, Dagan B, Gall GAE, Grossman M, Linskens HF, Zeeuw D de (eds) Monographs on theoretical and applied genetics, vol 2. Springer, Berlin Heidelberg New York

Fuchs C (1963) Fuchsin staining with NaOH clearing for lignified elements of whole plants or plant organs. Stain Technol 38:141-144

Galli MG (1984) Synthesis of DNA in excised watermelon cotyledons grown in water and benzyladenine. Planta 160:193199

Galli MG, Bracale M, Falavigna A, Soave C (1988) Sexual differentiation in Asparagus officinalis L. I. DNA characterization and mRNA activities in male and female flowers. Sex Plant Reprod 1:202-207

Gasser CS, Budelier VA, Smith AG, Shah DM, Fraley RT (1989) Isolation of tissue-specific cDNAs from tomato pistils. Plant Cell 1:15-24

Goldberg RB (1988) Plants: novel developmental processes. Science $240: 1460-1467$

Hurkman WJ, Tanaka CK (1986) Solubilization of plant membrane proteins for analysis by two-dimensional gel electrophoresis. Plant Physiol 81 :802-806
Lazarte JE, Palsen BF (1979) Morphology, vascular anatomy and embryology of pistillate and staminate flowers of Asparagus officinalis $\mathrm{L}$. Am J Bot 66:753-764

Lopptlen H (1979) Identification of the sex chromosome pair in Asparagus (Asparagus officinalis L). Z Pflanzenzücht $82: 162-163$

Marks M (1973) A reconsideration of the genetic mechanism for sex determination in Asparagus officinalis L. Proceedings of the Eucarpia Meetings on Asparagus, Versailles, pp 123-128

Meeks-Wagner DR, Dennis ES, Tran Thanh Van K, Peacock WJ (1989) Tobacco genes expressed during in vitro floral initiation and their expression during normal plant development. Plant Cell 1:25-35

Mollenhauer HH (1964) Plastic embedding mixtures for use in electron microscope. Stain Technol 39:111-114

O'Farrell PH (1975) High resolution two-dimensional electrophoresis of proteins. J Biol Chem 250:4007-4021

Simoens CR, Peleman J, Valvekens D, Von Montagu M, Inzé D (1988) Isolation of genes expressed in specific tissues of Arabidopsis thatiana by differential screening of genomic library. Gene 67:1-11

Westergaard M (1958) The mechanism of sex determination in dioecious flowering plants. Adv Genet 9:217-281 